\title{
Gynaecological Minimal Access Surgeries Performed in a Tertiary Health Institution in North Western Nigeria: A Five Year Review
}

\author{
Panti $\mathrm{AA}^{1}, \mathrm{Umar} \mathrm{AG}^{2}$, Temitope $\mathrm{AO}^{3}$, Adoke $\mathrm{AU}^{3}$, Ibrahim $\mathrm{R}^{3}$, Bello $\mathrm{S}^{3}$ \\ ${ }^{1}$ Professor, Department of Obstetrics and Gynaecoogy, Usmanu Danfodiyo University, Sokoto, Nigeria \\ ${ }^{2}$ Department of Obstetrics and Gynaecoogy, Usmanu Danfodiyo University, Sokoto, Nigeria \\ ${ }^{3}$ Department of ObstetricSs and Gynaecoogy, Usmanu Danfodiyo University Teaching Hospital, Sokoto, Nigeria
}

DOI: $10.36348 /$ sijog.2020.v03i03.003

| Received: 04.03.2020 | Accepted: 13.03.2020 | Published: 21.03 .2020

*Corresponding author: Abubakar A. Panti

\section{Abstract}

Background: Minimal access surgery offers patients fewer postoperative complications, shorter hospital stay and better cosmetic results compared to conventional open gynaecological surgeries. Aim and Objectives: To determine the prevalence of gynaecological minimal access surgeries and to determine indications and complications associated with them at UDUTH, Sokoto, Nigeria. Methodology: This was a descriptive retrospective study of all gynaecological laparoscopies and hysteroscopies performed at the Usmanu Danfodiyo from $1^{\text {st }}$, January 2012 to $31^{\text {st }}$, December 2016. Result: There were 1,016 gynaecological surgeries over the period with 112 minimal access surgeries given a prevalence of $11.02 \%$. Laparoscopy accounted for $87.1 \% \%$ while, hysteroscopy was $12.9 \%$ of cases. Their ages ranged from 18 to 40 years with a mean of $28.44 \pm 4.99$ years, and a modal age of $25-34$ years $(66.6 \%)$. Laparoscopy accounted for $87.1 \%$ of the minimal access surgeries while hysteroscopy was $12.9 \%$. Secondary Infertility $(41.1 \%)$ is the most common indication for laparoscopy followed by primary infertility $(28.9 \%)$ and amenorrhea (15.6\%). Asherman's syndrome $(66.6 \%)$ is the commonest indication for hysteroscopy followed by secondary infertility $(16.6 \%)$. The most common complication was abdominal pain in $13.0 \%$ while, the least was uterine perforation in $0.9 \%$ among them. Conclusion: Minimal access surgery is a safe, feasible, and less invasive modality for evaluation and treatment of gynaecological pathologies. It has better cosmesis, less complications, and lower cost implication. Therefore, the need for training, retraining and provision of necessary facilities in Nigeria.

Keywords: Gynaecological surgeries, minimal access, Hysteroscopy, Laparoscopy, Infertility, Amenorrhea.

Copyright @ 2020: This is an open-access article distributed under the terms of the Creative Commons Attribution license which permits unrestricted use, distribution, and reproduction in any medium for non-commercial use (NonCommercial, or CC-BY-NC) provided the original author and source are credited.

\section{INTRODUCTION}

Endoscopy is a minimally invasive procedure, as it is the examination of the interior of a hollow viscous generally performed with a specialized instrument called endoscope [1]. Depending on the organ or cavity being visualized, endoscopy may be of various types. Gastroscopy (Stomach), Colonoscopy (Colon), Cystoscopy (Urinary bladder), Hysteroscopy (Uterus), Laparoscopy (Abdominal cavity) etcetera [1]. Laparoscopy is a transperitoneal endoscopic technique that provides excellent visualisation of the pelvic structures and often permits the diagnosis of gynaecologic disorders and pelvic surgery without laparotomy [2]. These endoscopic procedures are traditionally performed in the operating theatre under general anaesthesia [3, 4]. Minimal access surgery
(MAS) has continued to affect every area of gynaecology, from diagnosis to therapy, from reproductive medicine to urogynaecology and oncology [5]. The advantages are less post operative pain, shorter hospitalization and faster return to normal activities [5].

The endoscopic examination of the peritoneal cavity was first performed in dogs in the early 1900s by the German gynaecologist, Dr Georg Kelling who then called his procedure koelioscopie [6]. The first published work on laparoscopy in humans was by Dr Hans Jacobeus from Sweden in 1910 [6]. It was not developed for laparoscopy but rather for pneumothorax. This needle has remained the instrument for creating pneumoperitoneum to this day $[6,7]$. By the 1950 s the quartz rods were developed to improve illumination and 
the fibre-optic technology is what finally ended the problem of lighting [5-7].

Advantages of laparoscopy over laparotomy are small incision, excellent visualization of operative site, reduced postoperative pain, shorter hospital stay, early return to full activities, cosmetic advantages and less wound complication [2, 9]. Some of the disadvantages of laparoscopy are; difficulty in stopping bleeding, longer operative time, risk of visceral and vascular injury, expensive and specialized equipments, technically difficult and special training required.

The indications of laparoscopy are either diagnostic or therapeutic [2]. Some of the diagnostic indications are Pelvic pain, infertility, pelvic masses, genital tract anomalies, pelvic injuries, endometriosis and pelvic inflammatory disease $[1,2,10]$. While some of the therapeutic indications are tubal sterilization, adhesiolysis, missing intrauterine device, unruptured ectopic pregnancy, myomectomy, ova collection in IVF, ovarian drilling for polycystic ovaries, oophorectomy, hysterectomy and reconstructive surgery for pelvic organ prolapse $[1,2]$. The indications for hysteroscopy are; abnormal menstruation in women > 40 years, in women $<40$ years who are not responsive to medical treatment, inter-menstrual and post-coital bleeding despite normal cervical smear, postmenopausal bleeding, endometrial polyps, sub mucous fibroids, subfertility, recurrent miscarriage, Asherman's syndrome, congenital uterine anomaly and lost intrauterine contraceptive device [5]. The contraindications are intestinal obstruction, generalized peritonitis and intraperitoneal haemorrhage $[2,11]$.

In the industrialized countries, Minimal access surgery (MAS) is often the first choice intervention when surgery is needed. However, there is still a major gap in the implementation of laparoscopic surgery in resource limited settings often due to restricted availability or access to the equipment and lack of training $[12,13]$.

Three key innovations have generated a lot of interest in laparoscopy, these are; robotic surgery (Da Vinci surgery), natural orifice transluminal surgery (NOTES), and Laparoendoscopic single-site surgery (LESS) [7, 14].

The reported over all complication rates of laparoscopy surgeries range from $0.2 \%$ to $10.3 \%$ [12]. The complications of laparoscopy are significantly lower than conventional surgery though some may not be recognized during the procedure and are mainly entry-related [15]. The reported rates of these complications are 1.0-12.5/1,000, 3.6/1,000 and $5.7 / 1,000$ in the UK, Finland and Netherlands respectively [16].
In the USA, approximately 350,000 tubal ligations and 200,000 laparoscopically assisted vaginal hysterectomies are done annually, whereas in the UK, approximately 250,000 gynaecologic laparoscopic surgeries are performed annually [4]. In developing countries, particularly sub-Saharan Africa, gynaecologic laparoscopy was introduced in the 1970s through collaboration with donor agencies. It is still evolving and is mainly diagnostic for now [4]. In Kano, gynaecological laparoscopies accounted for 12\% [4] of all surgeries done in the department which is similar to Ilorin which accounted for $11.2 \%$ [12]. The minimal access surgeries done in these centres are mainly diagnostic.

The justification for this study is to review the gynaecological minimal access surgeries performed recently in UDUTH, Sokoto. Therefore, objectives of this study are; to determine the rate of gynaecological minimal access surgery at UDUTH, Sokoto, the indications, operative findings and complications associated with it.

\section{METHODOLOGY}

This study is a retrospective descriptive study of all gynaecological laparoscopies and hysteroscopies performed from $1^{\text {st }}$ January 2012 to $31^{\text {st }}$ December 2016 Case notes of patients that had laparoscopies and hysteroscopies over the period of study. Information regarding sociodemographic characteristics, indications for the surgeries, the types performed and complications associated with the procedures. The data obtained was analyzed using SPSS version 20. The result was presented in text, tables and charts.

\section{RESULTS}

There were 1016 gynaecological surgeries within the period under review with 112 being minimal access surgeries. Therefore, a prevalence of $11.02 \%$ or 112 per 1000 gynaecological surgeries was found for minimal access surgeries in gynaecology. Laparoscopy accounted for 95 cases and thus gave a prevalence of $9.35 \%$ or 93.5 per 1000 gynaecological surgeries. While hysteroscopy accounted for 19 cases and thus gave a prevalence of $1.87 \%$ or 18.7 per 1000 gynaecological surgeries. However, only 108 case files for both laparoscopy and hysteroscopy were available for analysis.

The age of the patients ranged between 18 years to 40 years with a mean of $28.44 \pm 4.99$ years. Majority $(66.6 \%)$ of the minimal access surgeries were carried out among the 25-34 year age group. Majority $68(63.0 \%)$ were unemployed and $70(64.8 \%)$ had at least secondary education. The Hausa/Fulani, $80(74.1 \%)$ were the dominant ethnic group and Muslims were the majority $90(83.3 \%)$ of the patients. Married women form the majority $(94.4 \%)$ and $76(70.4 \%)$ were nulliparous. 
Table-1: Sociodemographic characteristics of the patients

\begin{tabular}{|l|l|l|}
\hline Characteristics & Frequency & Percentage \\
\hline Age & & \\
(years) Less than 20 & 6 & 5.6 \\
20-24 & 16 & 14.8 \\
$25-29$ & 36 & 33.3 \\
30-34 & 36 & 33,3 \\
35 and above & 14 & $13 / 0$ \\
\hline Occupation & & \\
Unemployed & $\mathbf{6 4}$ & $\mathbf{6 3 . 0}$ \\
Student & $\mathbf{1 2}$ & $\mathbf{1 1 . 1}$ \\
Civil servant & $\mathbf{2 0}$ & $\mathbf{8 . 5}$ \\
Business women & $\mathbf{8}$ & $\mathbf{7 . 4}$ \\
Level of formal Education & & \\
\hline Non formal- 30,27.8 & & \\
Primary- 8, 7.4 & & \\
Secondary-442,40.7 & & \\
Tertiary- 26, 40.1 & & \\
\hline Tribe & & \\
Hausa/Fulani & $\mathbf{8 0}$ & $\mathbf{7 4 . 1}$ \\
Igbo & $\mathbf{2}$ & $\mathbf{1 . 9}$ \\
Yoruba & $\mathbf{1 0}$ & $\mathbf{9 . 3}$ \\
Others & $\mathbf{1 6}$ & $\mathbf{1 4 . 4}$ \\
\hline Religion & & $\mathbf{8 3 . 3}$ \\
Isla & $\mathbf{9 0}$ & $\mathbf{1 6 . 7}$ \\
Christianity & $\mathbf{1 8}$ & \\
\hline Marital status & & $\mathbf{8 3 . 3}$ \\
Married & $\mathbf{1 0 2}$ & $\mathbf{5 . 6}$ \\
Single & $\mathbf{6}$ & $\mathbf{7 6 . 4}$ \\
\hline Parity & $\mathbf{3 6}$ & \\
Nulliparae & $\mathbf{6}$ & \\
Primiparae & & \\
Multiparae & & \\
\hline & & \\
\hline
\end{tabular}

Secondary Infertility (41.1\%) is the most common indication for laparoscopy followed by primary infertility (28.9\%) and amenorrhea (15.6\%).
Asherman's syndrome $(66.6 \%)$ is the commonest indication for hysteroscopy followed by secondary infertility $(16.6 \%)$. Details are as shown on Figure-1.

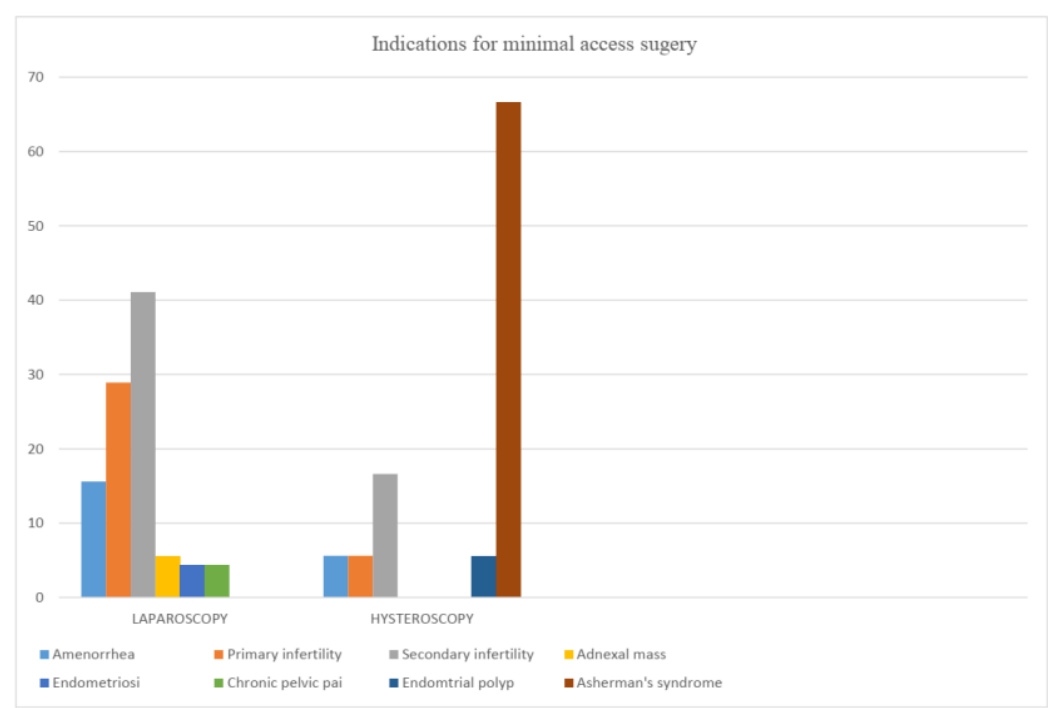

Fig-1: Indications for minimal access surgery 
Laparoscopy accounted for (90/108) $87.1 \%$ of the minimal access surgeries performed within the study period while hysteroscopy accounted for (18/108)12.9\%.

Laparoscopy and dye test, 50(46.3\%) was the most common laparoscopic procedure performed, while bilateral tubal blockage $46(35.1 \%)$ was the most common finding at laparoscopy. Diagnostic laparoscopy, $74(82.2 \%)$ is the main procedure performed in our centre. The two therapeutic laparoscopic procedures performed are laparoscopic ovarian drilling 10(9.3\%) and laparoscopic cystectomy $6(5.6 \%)$.

Hysteroscopy and adhesiolysis accounted for $12(11.1 \%)$ due to intrauterine adhesions which was the most common finding at hysteroscopy $13(72.2 \%)$. Details of types of surgeries performed is as in Figure-2 below.

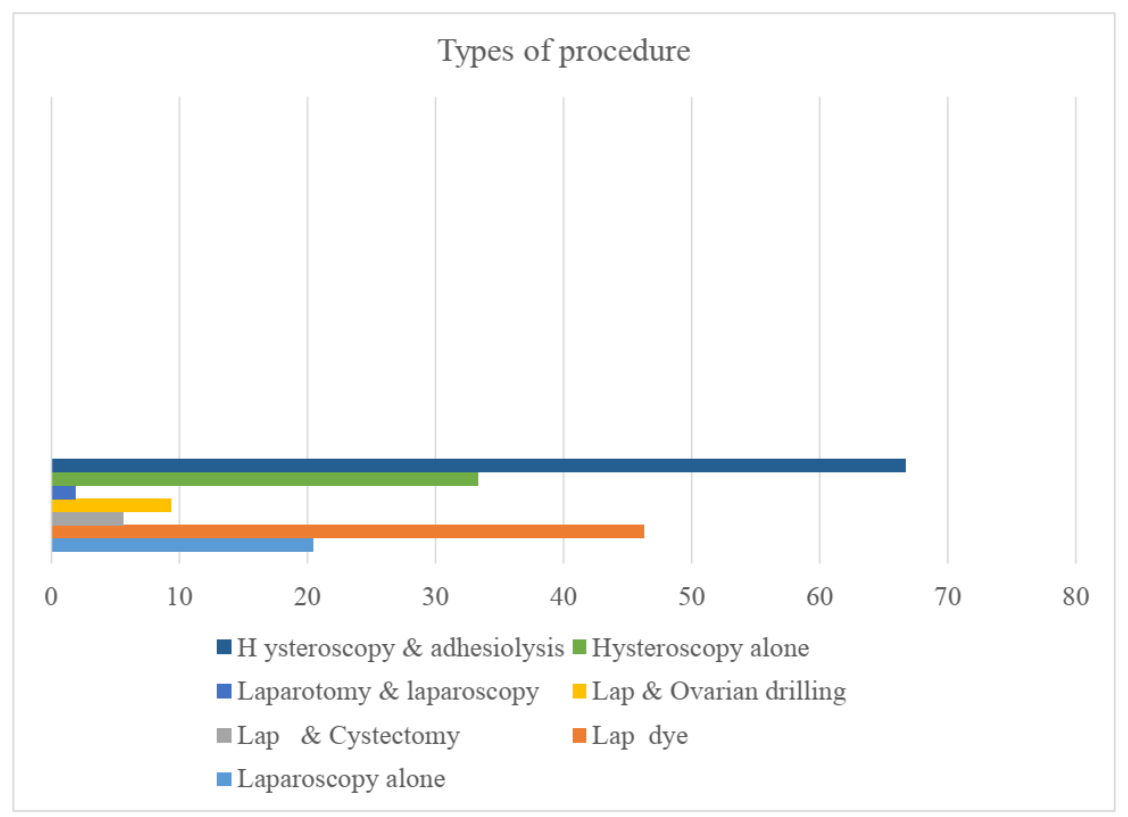

Fig-2: Types of procedure

Majority $85 \quad(78.6 \%)$ had no known complication following the procedures and the most common that occurred was mild abdominal pain 14 (13.0\%) that occurred in the laparoscopy arm and a, $(0.9 \%)$ case of uterine perforation among the hysteroscopy arm. Others accounted the other negligible complications. The mean duration of hospital stay was 2.8 days with least 1 day, 67 patients $(62.0 \%)$ to a maximum of 5 days in 1 patient $(0.9 \%)$ of cases. This shown on Figure $3 \& 4$.

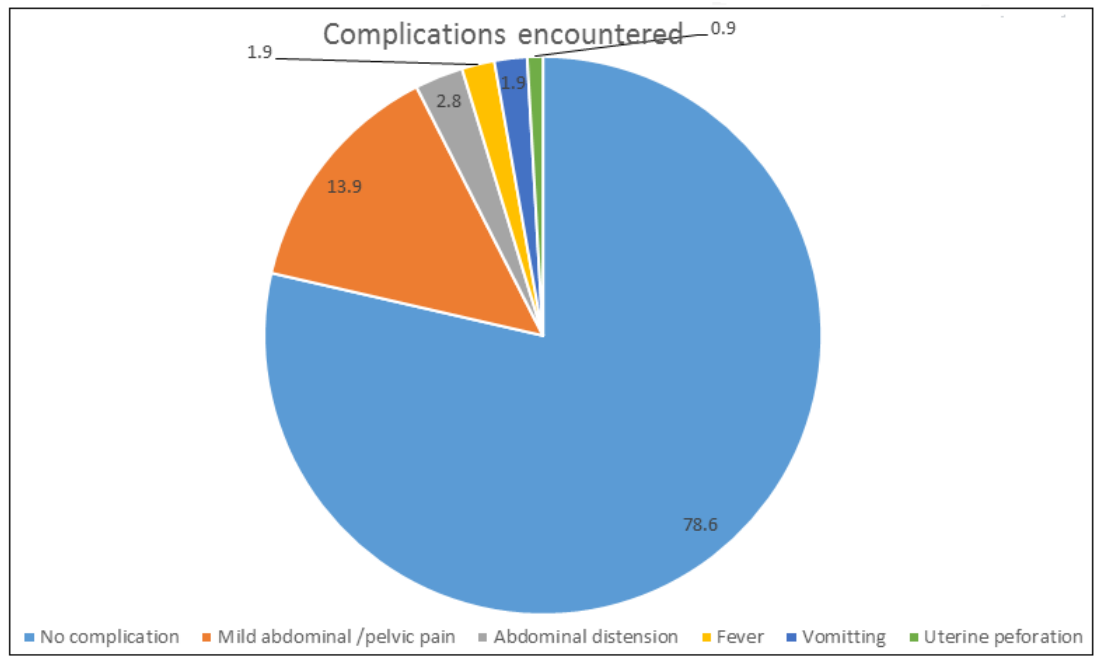

Fig-3: Complications of minimal access surgery 


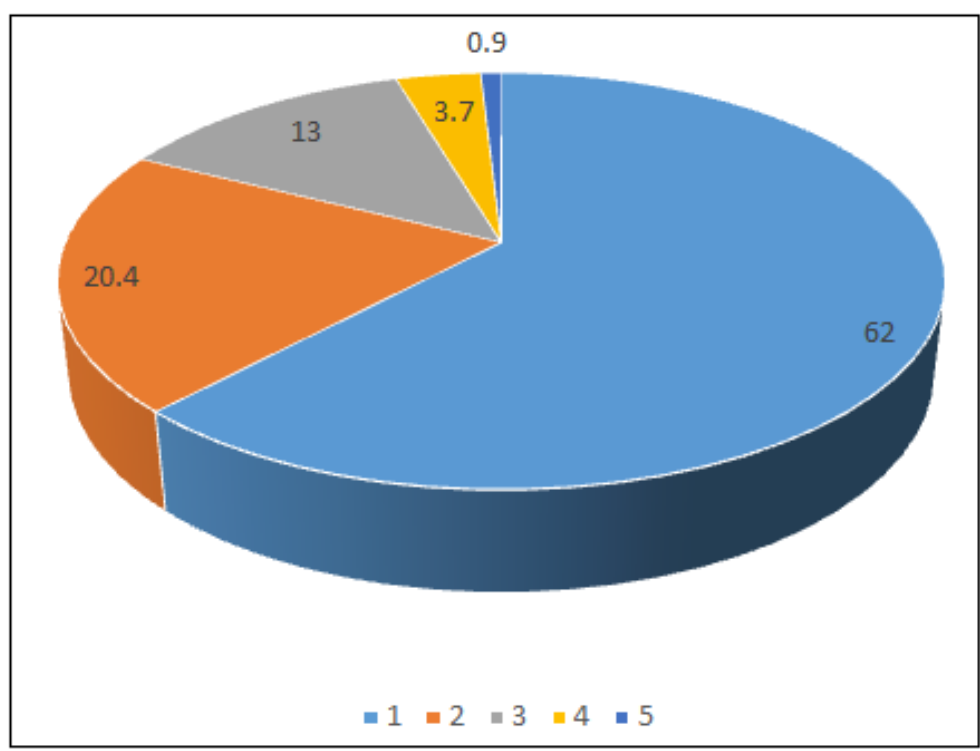

Fig-4: Duration of hospital stays in days

\section{DISCUSSION}

The rate of minimal access surgery (MAS) from this study is $11.02 \%$ or 112 per 1000 gynaecological surgeries, of which laparoscopy comprised of $9.35 \%$ and hysteroscopy comprised $1.87 \%$. This is similar to the $11.2 \%$ what was reported in Ilorin by Omokanye [12] and $12 \%$ in Kano by Yakasai [6], but much higher than the $2.87 \%$ found in Abuja by Efetie [23]. This low rate in Abuja was due to occasional logistic problems with the equipment. It is also higher than $6.9 \%$ reported from Yaoundé, Cameroon [15]. It is however, much lower than that obtained in developed countries like in the UK [2] where 250,000 gynaecological laparoscopic surgeries are performed annually [4], and it is often the first choice intervention when surgery is needed [12]. This may be due to few specialists and one laparoscope in our centre. Minimal access surgery from this study is mainly diagnostic as was reported from Abuja [23]. This is in contrast to the finding in Ilorin where most $(80 \%)$ of the laparoscopic surgeries performed were therapeutic [12].

Nulliparous women constituted $70.4 \%$ of the patients which is the majority and this finding is similar to what was reported from Cameroo [15]. This is because most of the patients had laparoscopy for either infertility or amenorrhea, hence the high percentage of nulliparous women.

From this study the most common indication for laparoscopy was infertility evaluation $70 \%$ (primary infertility $28.9 \%$ and secondary infertility $41.1 \%$ ), followed by amenorrhea $15.6 \%$. A previous study from this centre in 1999 also showed infertility to be the most common indication for laparoscopy followed by amenorrhea [21]. In similar studies from Abuja [23], Kano [4], Nnewi [25] and Cameroon 15, infertility was the most common indication followed by amenorrhea and chronic pelvic pain. The most common indication for hysteroscopy in this study is Asherman's syndrome $66.6 \%$ which was also the most common indication for hysteroscopy in Kano 52.1\% [4]. This is in contrast to the findings from a study in Italy, where the main indication for hysteroscopy was abnormal uterine bleeding $56.0 \%$ [26]. In this study, laparoscopy and dye test $(46.3 \%)$ was the most common procedure performed. It is also in agreement with report from Kano in which it was performed in two thirds of the study population [4]. This was not surprising because infertility was the most common indication for diagnostic laparoscopy in these centres. Only $1.9 \%$ had conversion to Laparotomy and this is similar to the $1.96 \%$ in Kenya [27]. It is higher than the $0.7 \%$ reported from Ilorin [12] but much lower than the 7\% reported by Golash [28]. The most common pathologic finding in laparoscopy was bilateral tubal block $(35.1 \%)$. This is similar to the $44.5 \%$ from Kano ${ }^{4}$. Majority $(78.6 \%)$ did not have any complication. Of those that had complication; abdominal pain $(13.0 \%)$ was the most common, unlike bladder and bowel injury which was reported in Kenya [27]. In this study, there was one case of uterine perforation $(0.9 \%)$ that occurred during hysteroscopy and adhesiolysis and warranted conversion to laparotomy. Sixty-two percent of the patients were discharged home within the first 24 hours after surgery. This is similar to the finding in Kenya where $64.5 \%$ spent one night after the procedure [27]. This is one advantage of such procedure, shorter duration of hospital stay, minimal use of resources and quick recovery. The mean hospital stay was 1.6 days \pm 0.9 unlike $3.4 \pm 1.8$ days from Cameroon [24]

\section{CONCLUSION}

Minimal access surgery surgeries is low in our centre and mainly diagnostic. It is however, safe, feasible, and less invasive modality for evaluation and treatment of many gynaecological pathologies with attendant benefit of shorter hospital stay, better 
cosmoses, less complications, and a lower cost implication in the long run. The most common indication for was for evaluation of secondary infertility, secondary amenorrhea. Therefore, efforts have to be intensified in training and provision of up to date facilities for Minimal access surgery in Nigeria.

Acknowledgement: We acknowledge the patients, records department and the management of the institution that granted permission for undertaking the research.

\section{REFERENCES}

1. Manchanda, R. (2011). Endoscopy in gynaecology. In: Salham, S. (Ed.) Textbook of Gynaecology $1^{\text {st }}$ ed. New Delhi: Jaypee; 538-546.

2. Wieslander, C. K., \& Wong, K. S. (2013). Therapeutic Gynaecologic Procedures. In: Decherney, A. H., Nathan, L., Laufer, N., \& Roman, S. (Eds). Current Diagnosis and Treatment: Obstetrics and Gynaecology $11^{\text {th }} \mathrm{ed}$. New York: McGraw Hill; 769-792.

3. Ikechebelu, J. I., Udigwe, G. O., Obi, R. A., JoeIkechebelu, N. N., \& Okoye, I. C. (2003). The use of simple ketamine anaesthesia for day-case diagnostic laparoscopy. Journal of Obstetrics and Gynaecology, 23(6), 650-652.

4. Avidime, A. R., Saidu, I., Muhammad, Z., Aisha, A., \& Adavuruku, S. S. (2016). Laparoscopy and hysteroscopy in a Tertiary Hospital: A 4 year review. Tropical Journal of Obstetrics and Gynaecology, 33(2), 205-208.

5. Magos, A. (2012). Hysteroscopy and Laparoscopy. In: Edmonds DE (Ed). Dewhurst's Textbook of Obstetrics and Gynaecology $8^{\text {th }}$ edition, Wiley Blackwell publishing, 36: 448-67.

6. Yakasai, I. A., Abdullahi, J., Omole-Ohonsi, A., \& Ibrahim, S. A. (2012). Gynaecologic Laparoscopy at Aminu Kano Teaching Hospital, Kano, Nigeria: A 5 year review. Br J Sci, 5(1), 11-17.

7. Hurd, W. W. (2015). Gynaecologic Laparoscopy, Rivlin ME (ed). E-medicine, Serial online. Date sited: December 28, 2015. Available at http.www.emedicine.com/article/265201-overview. (Accessed 25/02/2012).

8. O’Dowd, M. (2013). Standards for gynecologic surgery. The Journal of Obstetrics and Gynecology of India, 63(1), 7-13.

9. Enakpene, C. A., \& Ajayi, O. (2011). Evolution of Operative Laparoscopy in Gynecology: A Mirage or a Challenge? In: Darwish, A. (ed.) Advanced Gynecologic Endoscopy. Rijeka, Croatia: Intech; $1-12$.

10. Porpora, M. G., \& Gomel, V. (1997). The role of laparoscopy in the management of pelvic pain in women of reproductive age. Fertility and sterility, 68(5), 765-779.

11. Ates, M., Coban, S., Sevil, S., \& Terzi, A. (2008). The efficacy of laparoscopic surgery in patients with peritonitis. Surgical Laparoscopy Endoscopy
\& Percutaneous Techniques, 18(5), 453-456.

12. Omokanye, L. O., Olatinwo, A. W. O., Ibrahim, S., Durowade, K. A., Biliaminu, S. A., \& Abdul, I. F. (2017). Gynecological laparoscopic surgeries: A 4-year audit at the University of Ilorin Teaching Hospital, Nigeria. Tropical Journal of Obstetrics and Gynaecology, 34(1), 48-53.

13. Alfa-Wali, M., \& Osaghae, S. (2017). Practice, training and safety of laparoscopic surgery in low and middle-income countries. World journal of gastrointestinal surgery, 9(1), 13-18.

14. Fader, A. N., Levinson, K. L., Gunderson, C. C., Winder, A. D., \& Escobar, P. F. (2011). Laparoendoscopic single-site surgery in gynaecology: A new frontier in minimally invasive surgery. Journal of minimal access surgery, 7(1), 71-77.

15. Tchente, C. N., Mboudou, E., Tejiokem, M. C., \& Doh, A. (2009). Complications of laparoscopic surgery in gynecology unit A of Yaoundé General Hospital, Cameroon. Journal de gynecologie, obstetrique et biologie de la reproduction, 38(7), 545-551.

16. Royal College of Obstetricians and Gynaecologists. (2008). Green-top Guideline No. 49. Preventing entry-related gynaecological laparoscopy injuries. London: RCOG Press.

17. Kilonzo, A. (2010). The Role of Laparoscopy in the Management of Gynecologic Surgical Emergencies: A Review of Literature. World, 3(3), 127-130.

18. Ahmad, G., Baker, J., Finnerty, J., Phillips, K., \& Watson, A. (2012). Laparoscopic entry techniques. Cochrane Database Syst Rev, 15(2): CD006583.

19. Angioli, R., Terranova, C., Nardone, C. D. C., Cafà, E. V., Damiani, P., Portuesi, R., ... \& Panici, P. B. (2013). A comparison of three different entry techniques in gynecological laparoscopic surgery: a randomized prospective trial. European Journal of Obstetrics \& Gynecology and Reproductive Biology, 171(2), 339-342.

20. Jansen, F. W., Kolkman, W., Bakkum, E. A., de Kroon, C. D., Trimbos-Kemper, T. C., \& Trimbos, J. B. (2004). Complications of laparoscopy: an inquiry about closed-versus open-entry technique. American journal of obstetrics and gynecology, 190(3), 634-638.

21. Ekele, B. A., \& Oriaku, C. (1999). Diagnostic laparoscopy using room air pneumoperitoneum. Sahel Medical Journal, 2(2), 102-103.

22. Babar, M., Shah, W. B., \& Mehmood, K. T. (2010). Diagnostic Significance of laparoscopy in infertility \& identification of various unsuspected factors associated with infertility in females. Journal of Pharmaceutical Sciences and Research, 2(8), 499-505.

23. Efetie, E. R., Abubakar, J. S., \& Habeeb, S. A. (2009). Audit of gynaecological laparoscopies in national hospital Abuja, Nogeria. Nigerian journal 
of clinical practice, 12(2):149-152.

24. Mboudou, E., Morfaw, F. L., Foumane, P., Sama, J. D., Mbatsogo, B. A. E., \& Minkande, J. Z. (2014). Gynaecological laparoscopic surgery: eight years experience in the Yaoundé GynaecoObstetric and Paediatric Hospital, Cameroon. Tropical doctor, 44(2), 71-76.

25. Ikechebelu, J. I. (2013). Experience with diagnostic laparoscopy for gynecological indications. Nigerian journal of clinical practice, 16(2), 155-158.

26. Carta, G., Iovenitti, P., Buttari, F., D'Alfonso, A., \& Pestilli, S. (2003). Diagnostic hysteroscopy in the third millennium. Indications and role. Minerva ginecologica, 55(2), 159-165.

27. Parkar, R. B., Thagana, N. G., Baraza, R., \& Otieno, D. (2003). Experience with laparoscopic surgery at the Aga Khan Hospital, Nairobi. East
African medical journal, 80(1), 44-50.

28. Golash, V., \& Willson, P. D. (2005). Early laparoscopy as a routine procedure in the management of acute abdominal pain: a review of 1,320 patients. Surgical endoscopy and other interventional techniques, 19(7), 882-885.

29. Ucmak, H., Kokoglu, O. F., \& Buyukbese, M. A. (2013). Laparoscopic infections in urogenital and gynecological system: A systematic review. Archives of Clinical and Experimental Surgery (ACES), 2(1), 43-48.

30. Huang, Y. Y., Wu, H. L., Tsou, M. Y., Zong, H. J., Guo, W. Y., Chan, K. H., \& Ting, C. K. (2008). Paradoxical carbon dioxide embolism during pneumoperitoneum in laparoscopic surgery for a huge renal angiomyolipoma. Journal of the Chinese Medical Association, 71(4), 214-217. 